\title{
Further translocation of the Redclaw, Cherax quadricarinatus (Decapoda: Parastacidae), to Lake Ainsworth in northeastern New South Wales, Australia
}

Jesse C. Leland, Jason Coughran and James M. Furse

\begin{abstract}
The native Australian crayfish Cherax quadricarinatus (or Redclaw) is a large, highly fecund and fast growing species that has been widely translocated both interstate and internationally. This paper describes a translocated population of the species in Lake Ainsworth, an acidic coastal window lake in New South Wales. This population now represents the southern-most extent of its translocated range within Australia, and coincides with two native crayfishes, Cherax cuspidatus and a highly imperilled species of Tenuibranchiurus. Consistently high trap catches and collection of berried females indicates that the population in Lake Ainsworth is large, well established and selfsustaining. The probable pathway of introduction to the lake was by human action (deliberate or accidental), rather than natural dispersal from previous sites of introduction. Native crayfish were not captured in the lake, but their presence was confirmed in ephemerally connected habitats $\sim 2-3 \mathrm{~km}$ away. There are serious concerns about the further spread of the highly invasive $C$. quadricarinatus and its potential to displace native species.
\end{abstract}

\section{INTRODUCTION}

The Redclaw crayfish Cherax quadricarinatus (von Martens) is native to Queensland, the Northern Territory and New Guinea (Kailola et al., 1993; Lawrence \& Jones 2002; Wingfield, 2008) and is listed as Least Concern on the IUCN Red List (Austin et al., 2009). This tropical species is highly fecund, grows rapidly (harvestable size of $50-90 \mathrm{~g}$ in 8-12 months), matures quickly (between $\sim 30-70 \mathrm{~g}$ in 6-9 months), and can reach substantial weights of up to $590 \mathrm{~g}$ (Wingfield, 2002). Combined with its tolerance of extreme environmental conditions (e.g. water temperatures up to $34^{\circ} \mathrm{C}$ and poor water quality, including brackish water), these intrinsic qualities have facilitated the worldwide translocation of $C$. quadricarinatus for aquaculture research, commercial farming, recreational fishing (Horwitz, 1990; Kailola et al., 1993) and the aquarium trade (Peay et al., 2010). Recipient regions include the Americas, Europe, Asia and the Middle East (Lawrence \& Jones 2002) and, more recently, areas within Australia beyond its natural range (Coughran \& Leckie, 2007; Doupé, 2007; Doupé et al., 2007; Wingfield, 2008).

Translocation of crayfish species of commercial aquaculture potential (e.g. Procambarus clarkii (Girard) and Pacifastacus leniusculus (Dana)) (Anastacio et al., 1999; Gherardi et al., 2002; Peay et al., 2010) have been replicated in the Australian state of New South Wales (NSW), where both $C$. quadricarinatus and Cherax destructor Clark have been introduced (Coughran \& Leckie 2007; Coughran et al., 2009; Coughran \& Daly, 2012). Coughran \& Leckie (2007) described the first invasion of a NSW waterway (Emigrant Creek) by C. quadricarinatus and discussed the need for monitoring the translocation of this species. However, it appears that no funding or effort has been allocated to this objective, and no further reports of $C$. quadricarinatus translocation have been made since that time.

The presence of $C$. quadricarinatus in Lake Ainsworth, NSW was brought to the authors' attention in April 2011, when a recreational fisher was observed removing large adult crayfish from his traps. Lake 
Ainsworth $\left(28.78327^{\circ} \mathrm{S} 153.591936^{\circ} \mathrm{E}\right)$ is a relatively uncommon lake-type (perched freshwater window lake) that occurs along the east coast of central Australia (Timms, 1982). The geology of the area is dominated by basaltic and rhyolitic bedrock and soils from the former Tweed Volcano (Willmott, 1986). Lake Ainsworth was formed by coastal siliceous sand deposits overlaying the bedrock, and has a surface area of $\sim 0.12$ $\mathrm{km}^{2}$ with a maximum depth of $\sim 10 \mathrm{~m}$. As is typical in perched window lakes, $\mathrm{pH}$ is usually acidic $(\sim \mathrm{pH} 5.0)$ and salinity is low (70-115 ppm) (Timms, 1982).

Riparian vegetation includes various grasses and macrophytes, and the northern and southern landward extents of the lake are bordered by extensive coastal swamp and floodplain. The bordering Melaleuca swamps are inhabited by the native crayfish species Cherax cuspidatus Riek and Tenuibranchiurus sp. Riek (authors unpublished data and Coughran 2006a, 2006b). The former is classified as Least Concern, while the latter is considered an "Evolutionarily Significant Unit" (ESU, Moritz, 1994) by Dawkins et al. (2010) and therefore a very high conservation priority.

To our knowledge there have been no initiatives in funding, education, or field effort to reduce the spread of this exotic species since it was first reported in NSW. Of particular concern regarding this new population in Lake Ainsworth is that the species is now in immediate proximity to the only known site inhabited by the previously outlined Tenuibranchiurus sp., a highly imperilled native crayfish (Dawkins et al., 2010). In this paper, our aim was to (i) formally report the presence of the species and (ii) briefly discuss the implications for native crayfish in Lake Ainsworth.

\section{DISCUSSION}

To our knowledge, this is the first formal record of a $C$. quadricarinatus population in an acidic coastal window lake. The pathway of the species' introduction to Lake Ainsworth is unknown, but the lake is in the same catchment as the Emigrant Creek population, so a combination of movement through local waterways and overland migration is possible. However, more probable pathways include inadvertent "bait-bucket" transfer, aquarium discards, and intentional (and illegal) translocation/ stocking by recreational fishers.

Extensive trapping surveys and opportunistic observations of recreational fishers, indicate that large numbers of mature $C$. quadricarinatus can be captured irrespective of season and suggest that the population is well established (Leland unpublished data). Reproduction is occurring within the population as evidenced by the capture of berried females, which are extremely rare in trap catches, probably because of trap avoidance (Brown \& Brewis, 1978). Compared with males, females are disproportionally common and low numbers of juveniles in catches probably indicate similar behaviour, due to the presence of larger adult crayfish in or around the traps (i.e. trap size-selectivity Mitchell et al., 1994; Rabeni et al., 1997). Further studies to quantify the population characteristics are needed, with a view towards identifying best practises for controlling C. quadricarinatus in Lake Ainsworth.

The absence of native crayfish in catches is of some concern. It may be that $C$. quadricarinatus has displaced the smaller, native $C$. cuspidatus, which is otherwise ubiquitous in the area. However, it is also possible that native crayfish are present in the lake, and were simply avoiding the traps in the presence of the larger C. quadricarinatus. During 2010 and 2011, trapping and sweepnetting surveys of the adjacent Melaleuca swamp habitat $(\sim 2-3 \mathrm{~km}$ north of Lake Ainsworth) confirmed the presence of the native $C$. cuspidatus and Tenuibranchiurus sp. in the area (Furse unpublished data). During that time, C. cuspidatus were captured with the same bait traps in the Melaleuca swamp, which establishes the species was not generally 'trap shy' at that time. To date $C$. quadricarinatus have not been captured in any adjacent habitat by the authors or our colleagues.

Freshwater crayfish (including $C$. quadricarinatus) are well known for their ability to move overland (Riek, 1951; 
Olszewski, 1980; Furse et al., 2004; Coughran \& Leckie, 2007), and we are concerned about the further spread of this species. In particular, there is a serious concern regarding the potential of this species to disperse into adjacent, ephemerally interconnected swamps and waterways, especially to the north where the only known locality of the ESU Tenuibranchiurus sp. is situated, $\sim 2-3 \mathrm{~km}$ away from Lake Ainsworth. At a broader level, it also appears that the species may be being deliberately translocated in the northeastern NSW region, where it appears capable of establishing feral populations. This region supports several rare and endangered crayfish, fish and other aquatic species (e.g. amphibians): and introduced crayfish are well known for their capacity to displace native crayfish, fish and amphibian species (Horwitz, 1990; Harlioğlu \& Harlioğlu, 2006).

Research, management and public education imperatives for this exotic species were outlined by Coughran \& Leckie (2007), and we emphasise the need for the Local and State Government to address the previously outlined measures. Urgent action is needed to assess and monitor the spread of this highly invasive species in the northeastern NSW region.

Acknowledgements. - We extend our gratitude to Levi and Samara Leland for technical support and their assistance during our trapping expeditions. This research project was supported by the School of Environment, Science and Engineering, Southern Cross University (Lismore NSW) and the Environmental Futures Centre and Griffith School of Environment, Griffith University (Gold Coast campus, Queensland), Australia.

\section{LITERATURE CITED}

Anastacio, P. M., Nielsen, S. N. \& Marques, J. C., 1999. CRISP (crayfish and rice integrated system of production): 2. Modelling crayfish (Procambarus clarkii) population dynamics. Ecological Modelling, 123: 5-16.

Austin, C. M., Jones, C. \& Wingfield, M., 2009. Cherax quadricarinatus, In: IUCN Red List of Threatened Species (Version 2011.1). 2 pp, The
International Union for Conservation of Nature and Natural Resources. Gland, Switzerland.

Brown, D. J. \& Brewis, J. M., 1978. A critical look at trapping as a method of sampling a population of Austropotamobius pallipes (Lereboullet) in a mark and recapture study. Freshwater Crayfish, 4: $159-163$.

Coughran, J., 2006a. Field guide to the freshwater crayfishes of Northeastern New South Wales (Compact Disk Format). Natureview Publishing, Bangalow, NSW, Australia. ISBN: 0958114935.

Coughran, J., 2006b. Biology of the freshwater crayfishes of Northeastern New South Wales, Australia, Ph. D Thesis. School of Environmental Science and Management, Southern Cross University, Lismore, Australia.

Coughran, J. \& Daly, G., 2012. Potential threats posed by a translocated crayfish: the case of Cherax destructor in coastal drainages of New South Wales, Australia. Crustacean Research, Special Number 7: 5-13.

Coughran, J. \& Leckie, S. R., 2007. Invasion of a New South Wales stream by the Tropical Crayfish, Cherax quadricarinatus (von Martens). In: D. Lunney, P. Eby, P. Hutchings \& S. Burgin (ed.), Pest or Guest: the Zoology of Overabundance. Royal Zoological Society of New South Wales, Mosman, NSW, Australia, pp. 40-46, ISBN 978-0-9803272-1-2.

Coughran, J., McCormack, R. B. \& Daly, G., 2009. Translocation of the Yabby Cherax destructor into eastern drainages of New South Wales, Australia. Australian Zoologist, 35: 100-103.

Dawkins, K. L., Furse, J. M., Wild, C. H. \& Hughes, J. M., 2010. Distribution and population genetics of the threatened freshwater crayfish genus Tenuibranchiurus (Decapoda : Parastacidae). Marine and Freshwater Research, 61: 10481055.

Doupé, R. G., 2007. Where are they now? A baseline distributional description of introduced redclaw crayfish Cherax quadricarinatus (von Martens) in the east Kimberley region. Journal of the Royal Society of Western Australia, 90: 215218.

Doupé, R. G., Morgan, D. L., Gill, H. S. \& Rowland, A. J., 2007. Introduction of redclaw crayfish Cherax quadricarinatus (von Martens) to Lake Kununurra, Ord River, Western Australia: prospects for a 'yabby' in the Kimberley. Journal of the Royal Society of Western Australia, 87: 187-191.

Furse, J. M., Wild, C. H. \& Villamar, N. N., 2004. In-stream and terrestrial movements of Euastacus sulcatus in the Gold Coast hinterland: Developing and testing a method of accessing freshwater crayfish movements. Freshwater Crayfish, 14: 213-220.

Gherardi, F., Acquistapace, P., Tricario, E. \& 
Barbaresi, S., 2002. Ranging and burrowing behaviour of the red swamp crayfish in an invaded habitat: the onset of hibernation. Freshwater Crayfish, 13: 330-337.

Harlioğlu, M. M. \& Harlioğlu, A. G., 2006. Threat of non-native crayfish introductions into Turkey: global lessons. Reviews in Fish Biology and Fisheries, 16: 171-181.

Horwitz, P., 1990. The translocation of freshwater crayfish in Australia: potential impact, the need for control and global relevance. Biological Conservation, 54: 291-305.

Kailola, P., Williams, M., Stewart, P., Reichelt, R., McNee, A. \& Grieve, C., 1993. Australia's Fisheries Resources. Bureau of Resource Sciences and the Fisheries Research and Development Corporation, Canberra, ACT, Australia. ISBN 0642188769. 422 pp.

Lawrence, C. \& Jones, C., 2002. Crayfish of commercial importance: Cherax. In: D. M. Holdich (ed.), Biology of Freshwater Crayfish. Blackwell Science, Oxford, England. pp. 635666, ISBN 0-632-05431-X.

Mitchell, B. D., Collins, R. O. \& Austin, C. M., 1994. Multi-level refuge utilization by the freshwater crayfish Cherax destructor Clark (Decapoda: Parastacidae): a potential harvest and sampling technique. Aquaculture and Fisheries Management, 25: 557-562.

Moritz, C., 1994. Defining 'Evolutionarily Significant Units' for conservation. Trends in Ecology and Evolution, 9: 373-375.

Olszewski, P., 1980. A salute to the humble yabby. Angus and Robertson, Sydney, 150 pp, ISBN 0207140936.

Peay, S., Holdich, D. M. \& Brickland, J., 2010. Risk Assessments of Non-Indigenous Crayfish in Great Britain. Freshwater Crayfish, 17: 109-122.

Rabeni, C. F., Collier, K. J., Parkyn, S. M. \& Hicks, B. J., 1997. Evaluating techniques for sampling stream crayfish (Paranephrops planifrons). New Zealand Journal of Marine and Freshwater
Research, 31: 693-700.

Riek, E. F., 1951. The freshwater crayfish (family Parastacidae) of Queensland, with an appendix describing other Australian species. Records of the Australian Museum, 22: 368-388.

Timms, B. V., 1982. Coastal Dune Waterbodies of North-eastern New South Wales. Australian Journal of Marine and Freshwater Research, 33: 203-22.

Willmott, W. F., 1986. Rocks and landscapes of the Gold Coast hinterland: geology and excursions in the Albert and Beaudesert Shires. Geological Society of Australia (Qld. Division), Brisbane, Queensland, 38 pp, ISBN 0-959223-35-5.

Wingfield, M., 2002. An overview of the Australian freshwater crayfish farming industry. Freshwater Crayfish, 13: 177-184.

Wingfield, 2008. An Updated Overview of the Australian Freshwater Crayfish Farming Industry. Freshwater Crayfish, 16: 15-17.

Addresses: (* JCL) Marine Ecology Research Centre, School of Environment, Science and Engineering, Southern Cross University, Lismore, NSW 2480, Australia. (JC) Outback Ecology, 1/73 Troy Terrace, Jolimont, Western Australia, 6014, Australia, and Environmental Futures Centre and the Griffith School of Environment, Griffith University, Gold Coast campus, Queensland 4222, Australia. (JMF) Environmental Futures Centre and the Griffith School of Environment, Griffith University, Gold Coast campus, Queensland 4222, Australia;

Email: (JCL) jesse.leland@scu.edu.au, (JC) jason.coughran@outbackecology.com, (JMF) j.furse@griffith.edu.au

*Author for correspondence 